\title{
Compensating for past deforestation: assessing the legal forest surplus and deficit of the state of Pará, eastern Amazonia
}

Sâmia Nunes, Toby Gardner, Jos Barlow, Heron Martins, Rodney Salomão, Dyeden

Monteiro, Carlos Souza Jr.

\begin{abstract}
Up to $80 \%$ of each private rural property in the Brazilian Amazon is protected by law through the Legal Reserve (LR) mechanism of the federal Forest Code, underlining the conservation importance of forests on private lands in one of the world's most important biomes. However, our understanding of the discrepancies in levels of forest protection on private lands as obligated by the law versus what occurs in practice remains very poor. We assessed patterns of forest cover and legal compliance with the Forest Code in the $1.25 \mathrm{Mkm}^{2}$ Brazilian state of Pará, which has the highest deforestation rate in the Amazon. We evaluate the LR deficit and surplus patterns for different sized properties and across 144 municipalities, and found that the total LR surplus (12.6 Mha) was more than five times the total area of deficit (2.3 Mha). Yet, from the total surplus, only $11 \%$ can be legally deforested while the remaining $89 \%$ is already protected by law but can be used (sold or rented) to compensate for areas that are under deficit. Medium and large-scale properties make up most of the total LR deficit area, while agrarian reform settlements had comparatively large amounts of both compensation-only surplus and deforestable surplus. Most of the municipalities (77\%) in the state could compensate their total deficit with surplus areas of LR in the same municipality, while the remainder can be compensate their deficit in one or more neighboring municipality, indicating compensation can always take place close to the source of the deficit. Maximising the environmental benefits of achieving Forest Code compliance requires measures that go beyond the existing legal framework, including interventions to avoid further deforestation in places where it is still legal, compensate in close proximity to areas with legal reserve deficit and promote local restoration on degraded lands.
\end{abstract}

\section{KEYWORDS}

Forest restoration; Rural properties; Remote Sensing; Brazilian environmental policy; Legal Reserve; Spatial planning 


\section{INTRODUCTION}

Native vegetation covers about $60 \%$ of the national territory of Brazil, with $40 \%$ under some form of public protected area (conservation units and indigenous lands) and the remaining $60 \%$ located in private areas or public lands with no clear designation (Ferreira et al., 2012; Soares-Filho, 2013). The protection of forests on private land is therefore a vital part of any overall conservation strategy, helping sustain the delivery of critical ecosystem services, including maintenance of hydrological cycles, water quality, climate regulation through carbon sequestration and storage and the conservation of biodiversity (Daily et al., 1997; Nasi et al., 2002; Grimaldi et al., 2014).

In Brazil, the conservation of forest on private lands is regulated by the Brazilian Environmental Law (Law N 12.651, 25 March 2012) (Brazilian Federal Government, 2012b), commonly known as the Forest Code. This regulation divides rural properties into two areas: land for production and land dedicated to conservation and the sustainable management of natural resources. The latter is divided into two further categories: (i) permanent preservation areas (APP, in Portuguese) to protect particularly sensitive areas such as riparian vegetation, springs, steep slopes $\left(>45^{\circ}\right)$ and hilltops, where only low impact activities, such as ecotourism, are allowed; and (ii) Legal Reserves (LR) to promote the sustainable use of natural resources and the conservation of biodiversity. Economic activities, such as forest management for selective logging, are permitted in LRs under license but deforestation is not allowed. According to the updated Forest Code, last revised in October 2012, the definition of the LR area in a rural property is based on the Brazilian region where the property is located (e.g. LR is up to $80 \%$ in the Legal Amazon but only $20 \%$ in the other regions), the type of native vegetation (forest or savanna), the size of the property, region-specific regulations where LR reductions are allowed (e.g. areas that are zoned for agricultural development under state zoning plans) and the timing of deforestation (Brazilian Federal Government, 2012b).

Once the required LR area has been defined for each rural property, it is possible to estimate both the LR deficit, which is the shortfall of forest cover that is required to comply with the law, and the potential surplus, which is the forest cover additional to that required by law, expressed as a percentage of the total property area. The total surplus can also be disaggregated into that which is in excess of the LR requirement but which nevertheless cannot be deforested, yet can be used to compensate properties that 
are in deficit (termed here compensation-only surplus), and that which is in excess of the LR requirement but which can legally be deforested (i.e. for the Amazon biome areas of forest that are in excess of $80 \%$ of each property area, termed here deforestable surplus) (Figure 2). This distinction is of critical importance as the deforestable surplus is the only surplus that offers genuinely additional benefits for forest conservation (i.e. it is at risk of being cleared if not used to compensate properties with a LR deficit), whilst the compensation-only surplus is an important mechanism for providing monetary compensation to law-abiding landowners who did not deforest in the past.

In order to offset the LR deficit, the updated Forest Code provides two possibilities: forest restoration within the same farm that has the deficit, or compensation of LR deficit by acquiring, either by rent or purchase, the surplus of properties elsewhere. With the exception of APP areas this means that landowners can maintain their LR outside the boundaries of the farm that is in deficit without needing to retire land from production for restoration purposes. Trading for LR compensation can occur through mechanisms such as Environmental Reserve Quotas (CRA) and conservation easements (Brazilian Federal Government, 2012b; Zakia and Pinto, 2013), with an increasing number of initiatives seeking to facilitate such exchanges (such as the online legal reserve market place offered by Bolsa Verde Rio: www.bvrio.org).

However, land tenure uncertainties, e.g. land ownership rights and location of properties, make it difficult to conduct an accurate assessment of land cover in rural properties or implement environmental legislation effectively (Barreto et al., 2008; Brito and Barreto, 2011). To address this, the Brazilian government created the Environmental Rural Property Register (CAR, in Portuguese, first introduced in the state of Pará in 2006), a mandatory georeferenced register of private properties, that has been instrumental in helping to both assess and promote compliance with environmental regulations, curb deforestation and foster more effective economic and environmental planning. The updated Forest Code states that by the $5^{\text {th }}$ of May 2016, all rural properties in the country must be registered in CAR (Brazilian Federal Government, 2012b, 2012a).

Despite Brazil having some of the world's most stringent environmental regulations for the legal protection of native vegetation in private properties, the extent of private reserve surpluses and deficits has hitherto been very poorly assessed, and never at the scale of an entire state. Although Soares-Filho et al. (2014) assessed compliance with the Forest Code at the scale of the entire country, a lack of data on 
property boundaries meant that they used micro-catchments as their unit of analysis. The lack of more detailed assessments can be explained by: (i) the historic lack of a minimally accurate and representative georeferenced register of private properties for any Brazilian state - a task further hampered by insufficient technical expertise within state governments to validate CARs declared by property owners themselves; (ii) a lack of detailed and reliable Geographic Information Systems (GIS) and remote sensing products, especially for the Amazon region - including water course mapping at a 1:50.000 scale as required by law (Souza Jr. et al., 2013) and land cover maps with a resolution consistent with the scale of individual properties; and (iii) the complexity of Brazilian environmental laws that have led to uncertainty, misunderstandings and controversies among different sectors (e.g. government, NGOs and farmers) on how to apply regulations and estimate legal liabilities (Ellinger and Barreto, 2012; Vale et al., 2014; Vieira et al., 2014). Taken together, these barriers have undermined effective law enforcement, compliance monitoring and more sustainable land-use planning of private properties.

Here we estimate the total LR deficit and surplus for the state of Pará, which covers around 25\% of the Brazilian Amazon, and compare levels among different sized properties and across 144 municipalities. We focus on Pará, the second largest state in Brazil, because: (i) it is the most advanced state in the Amazon in registering its private rural properties in the CAR system; $>60 \%$ of the area suitable for registry was included in the state government database by 2014; (ii) it currently has one of the highest rates of deforestation in the Amazon: an average of 2,000 $\mathrm{km}^{2} /$ year from 2011 to 2015, compared to $5,500 \mathrm{~km}^{2} /$ year for the whole Brazilian Amazon, and (iii) state and municipal governments of Pará, together with civil society, have been particularly active in their efforts, to reduce deforestation and the state has been recognized as setting an example for other parts of the Amazon, eg. through Para's Green County initiative. We address four specific questions: (i) What is the LR deficit and surplus for the entire state of Pará?; (ii) What proportion of the total surplus can be considered deforestable versus compensation-only surplus? (iii) How is the total deficit and surplus for the state distributed across properties of different sizes?; and (iv) What is the capacity of each municipality to compensate its LR deficit within the same or adjacent municipalities?

\section{METHODS}




\subsection{Study area}

Our analysis is focused on the state of Pará, located in the eastern Brazilian Amazon (Figure 1). Pará is the second largest state in Brazil, larger than many countries (e.g. Peru, South Africa) and intersects five of the key areas of endemism in the Amazon. It has an estimated population of 8 million people, with an area of 1.25 million $\mathrm{km}^{2}$, encompassing 144 municipalities and with a Gross Domestic Product of R $\$ 88.3$ billion (IBGE - Brazilian Institute of Geography and Statistics, 2014), mostly from the extractive industry (e.g. iron, bauxite, wood, charcoal), agriculture (e.g. palm oil and cassava) and cattle ranching (Pará has the fifth largest cattle herd in Brazil - with 17 million heads in the 2013 census) (IBGE - Brazilian Institute of Geography and Statistics, 2013).

Pará has about $55 \%$ of its territory, or $685,575 \mathrm{~km}^{2}$, protected by law in sustainable-use, strictly protected, or indigenous reserves (Brazilian Ministry of the Environment and National Indian Foundation, 2013). However, it also had one of the highest rates of deforestation in the Amazon, which is related to the pattern of recent occupation and agricultural expansion incentivized by the construction of highways, the development of large-scale industries, such as energy and mining, and the expansion of agriculture and cattle ranching (Whately and Campanili, 2013). In response to this, the Federal government launched a major program in 2004 to combat deforestation in the Amazon, the Action Plan for Prevention and Control of the Legal Amazon Deforestation (PPCDAm in Portuguese), which encompassed a set of command, control and monitoring measures, as well as large-scale reserve expansion. These measures helped reduce deforestation across the biome by more than $80 \%$ from 2004 to 2012 (MMA - Brazilian Ministry of the Environment, 2004; Whately and Campanili, 2013). In this context, the State Government of Pará also launched the Green Municipalities Program in 2011 in partnership with municipalities, civil society, private initiatives and the Public Prosecution Service.

One of the main goals of the Green Municipalities Program is to control deforestation by increasing the property area registered under the CAR system. According to the program, Pará had more than $60 \%$ of its private land registered in the CAR system by 2014 (Green Municipalities Program, 2014). However, the tenure situation of private land across Pará remains in a confused state, with $39 \%$ of the territory - mainly the eastern portion - presenting tenure irregularities. The remaining 
$61 \%$ that has defined tenure includes protected areas, agrarian reform settlements and registered properties.

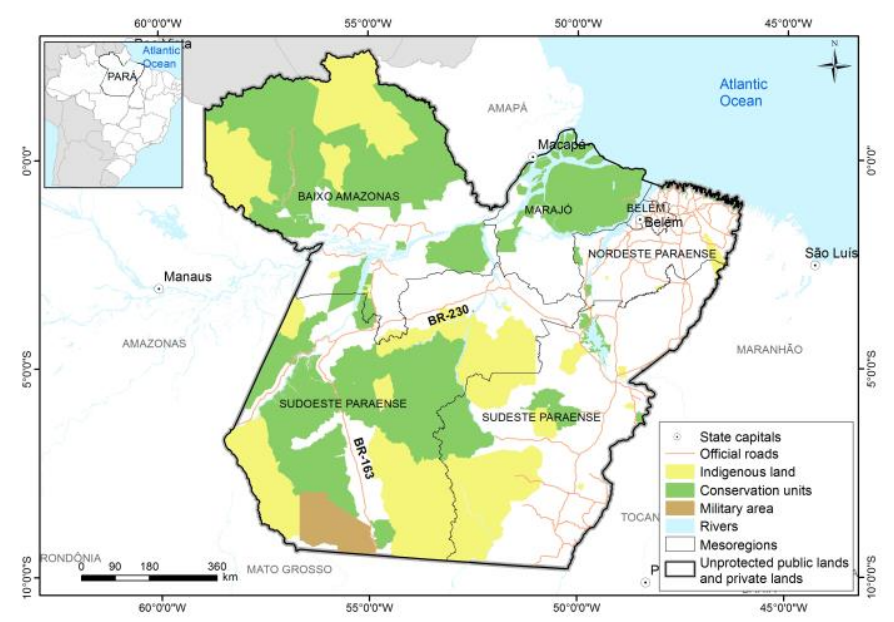

Figure 1: Study area, state of Pará, located in the Brazilian Amazon, northern Brazil.

\subsection{Accounting for Legal Reserve deficit and surplus}

We analyzed approximately 57,890 properties registered in the CAR system and 945 agrarian reform settlements (set of small rural properties created by the Rural Settlement and Agrarian Reform - INCRA - for low income families), amounting to 58,835 registered areas. We excluded all protected areas from this analysis as our focus is on compliance in private lands. Estimating LR deficit and surplus in Pará required us to reduce the overlap between geographic databases, define the LR percentage for each property, and estimate LR deficit and different types of surplus for each property (Figure 2). We then used this to estimate the LR balance across the state of Pará and within all municipalities based on the Brazilian Forest Code regulations. These analytical steps are summarized in Figure 3, and described in detail below. 

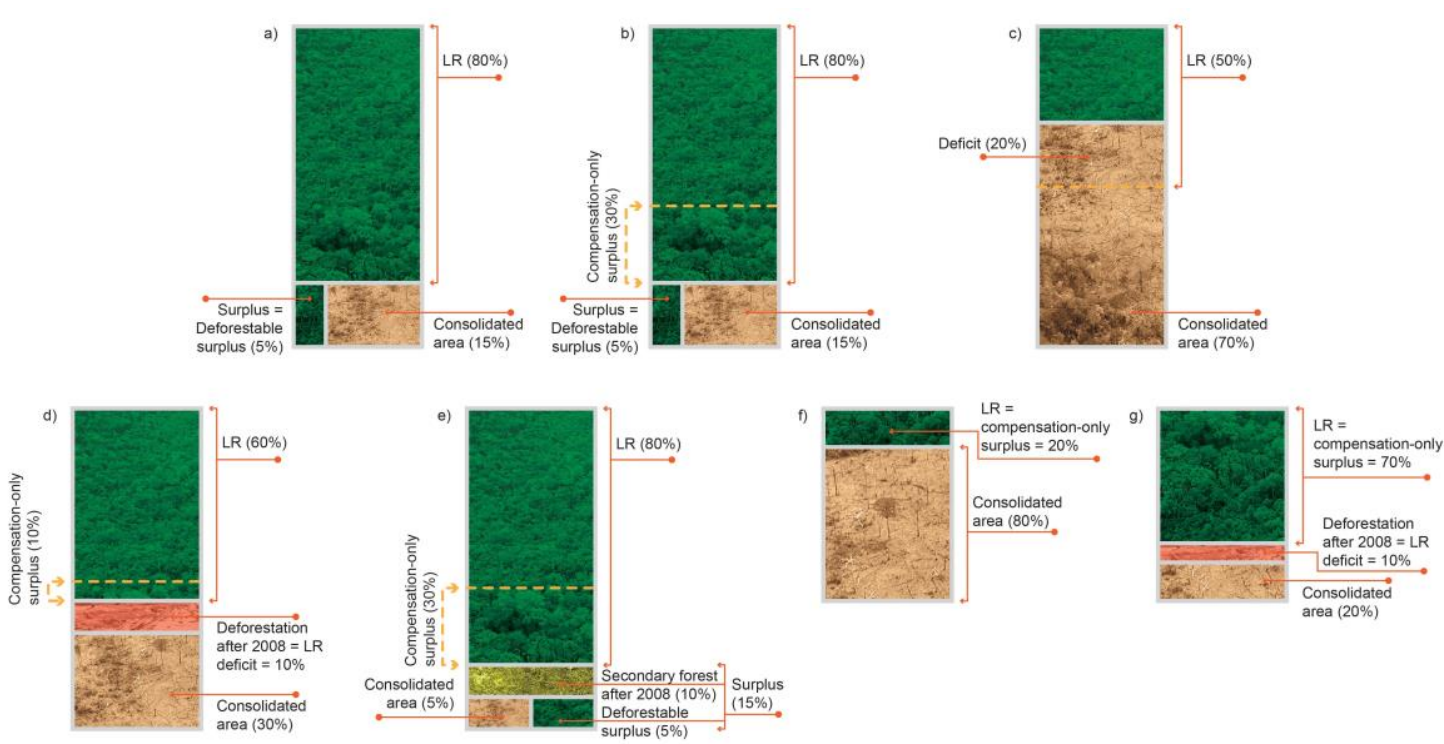

Figure 2: Examples of LR deficit and different types of surplus per private property based on the updated Forest Code definitions: a) deforestable surplus for both medium/large properties located where LR reduction is not allowed. The minimum LR permitted is $80 \%$ of each property and only areas of forest in excess of this percentage can be deforested; b) compensation-only surplus and deforestable surplus for medium/large properties located in situations where LR reduction is allowed. Forest cover from $50 \%-80 \%$ cannot be deforested but can be used for compensation in medium/large properties and forest cover above $80 \%$ can be deforested; c) LR deficit where LR reduction is allowed. The land owner must restore forest up to $50 \%$ of the property; d) deficit (deforestation after 2008) and compensation-only surplus for medium/large properties located in situations where LR reduction is allowed; e) compensation-only surplus and total surplus for medium/large properties where reduction is allowed; f) compensation-only surplus for small properties that is the same as the LR and g) deficit (deforestation after 2008) and compensation-only surplus for small properties which again is the same as the LR. 


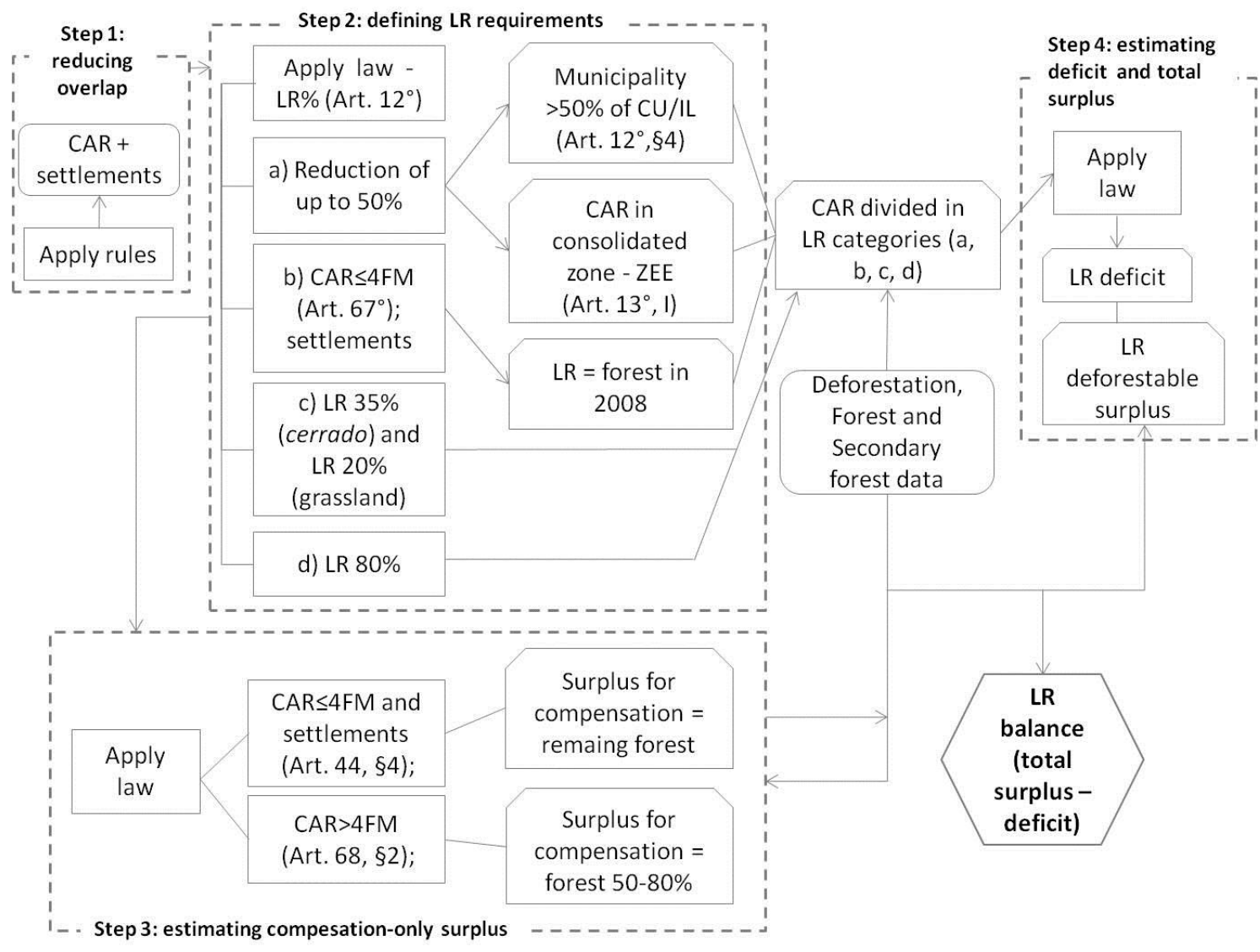

Figure 3: Summary of the methodology applied to estimate deficit and surplus of Legal Reserve in private properties in the state of Pará. The definition of the Legal Reserve percentage was based on four main criteria: (a) reduction of up to $50 \%$ for properties located in specific regions; (b) LR for properties up to 4 fiscal modules (FM) and settlements; (c) LR of $35 \%$ or $20 \%$ for non-forest vegetation areas (cerrado and grassland, respectively) and (d) LR of $80 \%$ for all properties where the other specific rules do not apply. LR stands for Legal Reserve; CAR - Environmental Rural Property Register; CU - Conservation Units; IL - Indigenous Land and ZEE - Ecological and Economic Zoning plan.

\subsubsection{Reducing overlap between properties registered in CAR}

The property database used in this study is restricted to the areas that can be registered in CAR, and therefore excludes indigenous lands, conservation units (except Areas of Environmental Preservation - APA, in Portuguese, where production land-uses are permitted), military lands and water bodies. The first phase of registering a private property in the CAR system involves contributing to a temporary registration (called a "provisional CAR") that is then validated by the state government (when it then becomes a "definitive CAR"). However, due to the lack of technical capacity and 
accurate base maps, only a small portion (1\%) of the CARs for the state of Pará, and the country more generally, have been validated (State Environmental Secretary, 2015). As a result there are a large number of errors and disputes over farm boundaries. Reducing the overlap between rural properties in the temporary CAR was therefore the first step towards obtaining more precise information regarding the Legal Reserve deficit and surplus for the state. We estimated an initial total overlap of $6.8 \mathrm{Mha}$, that is, $24 \%$ of the total area that is registered under the CAR. To reduce the area of overlap in farm boundaries we adopted the following criteria:

a) Where properties have the same CAR code, the most recent entry was considered because there may be more than one version of the same property in the database;

b) Where there was an overlap greater than $5 \%$ between an approved CAR and a provisional CAR issued before the former's approval, the property with the provisional CAR was excluded; No properties were excluded where the overlap was less than $5 \%$ (allowed by law);

c) Where overlap was greater than $80 \%$, the smallest property was excluded;

d) Where properties were obviously duplicated in the system (i.e. they occupied exactly the same area and had exactly the same size), one of them was excluded at random;

e) Properties with an overlap larger than $30 \%$ with agrarian reform settlements were excluded;

f) Properties that overlapped more than $50 \%$ with water bodies were excluded, in addition to those that were located more than $50 \%$ in areas not suitable for registry (areas where CAR is not permitted). For example, properties located in Indigenous lands.

These criteria were combined into an algorithm developed in ArcGIS Python 2.7 and, after being applied to the CAR database, the overlap decreased to 667,000 ha - a reduction of $90 \%$ (6 Mha) compared to the initial total overlap.

\subsubsection{Defining Legal Reserve according to the updated Brazilian Forest Code}

A set of regulations present in the Brazilian Forest Code define the percentage of LR in rural properties (Figure 2 and 3; see Tables S2 and S3 for a summary). In general, rural properties with forest areas located in the Brazilian Amazon must have a LR of 
$80 \%$ of each property's total area. However, there are several conditions that allow reduction of this initial percentage for forest restoration or compensation purposes (not deforestation) (Table S3). It means that the only portion that can be deforested is that in excess of $80 \%$ forest cover in a given property. However, properties that deforested more than $50 \%$ in the past must restore or compensate back up to $50 \%$, not $80 \%$. The rules applied to define LR were:

a) Areas with a possible reduction of up to $50 \%$ of the Legal Reserve in the property area: according to Art. $12, \S 4$, the minimum LR requirement can be reduced from 80 down to a minimum of $50 \%$ of each property area (for restoration purposes) when the municipality in which the property is located has more than $50 \%$ of its area protected by public Conservation Units (CUs, excluding APAs that may be occupied by private lands) and/or Indigenous Lands (ILs) (Fig. S1). The LR can also be reduced down to a minimum of $50 \%$ of the area of each property (exclusively for regularization whether through on-farm restoration or off-farm compensation) when properties are located in areas designated for agricultural activities, and as indicated in the Ecological and Economic Zoning plan of the State (Art. 13, I). In order to comply with this regulation, we distinguished whether properties were located within the consolidated areas of the Ecological and Economic Zoning plan developed by the state Environmental Secretary (SEMAS-PA), excluding water resource areas, and identifying consolidated areas (areas deforested before 22nd July 2008) inside this zone.

b) Legal Reserve for properties smaller than four fiscal modules on 22nd July 2008: A Fiscal Module (FM) is a Brazilian government agrarian measurement that represents the minimum area of an economically feasible rural property. One Fiscal Module ranges from 5 to 110 ha, depending on the municipality (Landau et al., 2012). For rural properties that have an area of up to four fiscal modules on 22nd July 2008 the LR is defined as the area under native vegetation as of 22nd July 2008 (Art. 67), thereby providing an amnesty for many smallholders who would otherwise have to restore or compensate for historical deforestation (Soares-Filho et al., 2014). In this case we selected current properties with up to four fiscal modules, since there is no CAR data for 2008, and compared them with the current forest cover to verify the percentage of native vegetation for each property. Those with deficits were then crossed with the forest cover of 2008 to determine the properties current LR requirement. The same criteria were used for rural settlements as they are largely dominated by small holdings of standard size. 
c) Legal Reserve for vegetation other than forest: according to Art. 12, item I, cerrado vegetation and grassland areas in the Brazilian Amazon have a LR requirement of $35 \%$ and $20 \%$, respectively, of the total property area. It was not possible to account for the deficit or surplus of these two vegetation types because PRODES (Brazil's Federal government deforestation monitoring program for the Amazon) data do not include deforestation in cerrado and grassland areas, which is much harder to detect. The total area of cerrado or grassland mapped by PRODES was $1.8 \mathrm{Mha}$ or $8 \%$ of the total CAR analyzed area. We considered properties with cerrado or grassland areas larger than $50 \%$ of the property area as neutral (no deficit or surplus), to reduce the risk of bias. For those with less than $50 \%$ of cerrado or grassland we assumed that they were forested and applied the other criteria accordingly.

d) Legal Reserve in remaining areas: rural properties that were not eligible for any of the reduction conditions described above had their LR percentage defined as $80 \%$ of each property area, according to the default LR requirement for the Amazon biome as established in the updated Brazilian Forest Code.

Deforestation data used to estimate LR deficit is based on the cumulative PRODES up to 2012 less the area of secondary forest detected by TerraClass (Brazil's federal government land-use monitoring project for the Amazon) in the same area. The total forest area is the sum of forest detected by PRODES with the secondary forest detected by TerraClass (forest at advanced stage of regeneration) in areas previously detected as deforestation by PRODES. Deficits in APPs were not accounted for in this study due to the lack of a more detailed and reliable hydrography mapping (1:50.000) at the scale of Pará, required by Decree $N^{\circ} 7.830,17$ October 2012 for the National CAR System.

\subsubsection{Estimating compensation-only LR surplus and defining types of LR surplus}

We considered the following regulations of the Forest Code to estimate the surplus that is available for deficit compensation only (i.e. areas of forest that cannot be deforested): (i) for small properties or family holdings, any remaining native vegetation area under $80 \%$ of each property is considered as compensation-only surplus (Art. 44, $\S 4$ ); (ii) for medium and large properties that have forest cover greater than $50 \%$ and less than $80 \%$, this range of forest cover is considered a compensation-only surplus where LR reduction is allowed (Art. 68, §2) (Figures 2, 3; Table S2). 
The number of opportunities provided by the Forest Code to compensate LR deficit makes it possible for properties to present, at the same time, a deficit (e.g. deforestation of native forest within LR after 22nd July 2008) and surplus for compensation (compensation-only surplus). For example, for the cases where LR reductions are allowed, a large property with $70 \%$ of forest cover in 2008 , but where the landowner deforested an area of $10 \%$ after 2008, would present a LR deficit of $10 \%$. But at the same time, the property presents a LR surplus of $10 \%$ that would be available to compensate the deficit of other properties, if the area is not embargoed, since forest cover of $50-80 \%$ of the property can be used to compensate LR deficit (Table S2). However, due to the persistent lack of clear regulations at the state level, many uncertainties remain regarding the application of compensation mechanism.

The LR deforestable surplus is defined as areas of forest that are surplus to the legally required LR, and can therefore be legally deforested (forest cover over $80 \%$ of each property). This does not include areas of forest that are additional to the minimum cover stipulated by reduced compliance requirements in areas that have been historically deforested. For example, for medium and large properties in areas zoned for agricultural activities with more than $50 \%$ but less than $80 \%$ cover, the forest cover that is additional to $50 \%$ can be used to compensate for properties that are in deficit (termed compensation-only surplus), but cannot be deforested. The total area of forest available for compensation schemes is the sum of the deforestable surplus and the compensationonly surplus (termed here total surplus) (Table S2).

\section{RESULTS}

Of the total required Legal Reserve area in Pará (21.2 Mha), 10.7\% (2.3 Mha) was classified as a LR deficit; 6.4\% (1.3 Mha) as deforestable surplus and 53.1\% (11.3 Mha) as compensation-only surplus (Figures 4, 5 and Table S4). The remaining area is covered by forest that cannot be deforested or used for compensation.

\subsection{Distribution of Legal Reserve deficit in Pará}

A total of 23 Mha of CAR and 12 Mha of rural settlements were analyzed in this study, accounting for $29 \%$ of the surface area of Pará and $61 \%$ of its registerable area. The estimated total forest deficit in Pará covers 2.3 Mha and is made up by properties in CAR and rural settlements (Fig. 4a). The LR deficit in CAR corresponds to an area of $\sim 2$ Mha ( $87 \%$ of the total deficit). The majority of this $(50.4 \%)$ is within properties that 
have $0-30 \%$ deficit, while $48.2 \%$ is within properties that have $30-60 \%$ deficit and the remaining $1.4 \%$ for properties that have $60-80 \%$ deficit (Figure 4a; Table 1). Settlements were found to contain a deficit of 300,389 ha - about $13 \%$ of the total LR area requirement for this type of land tenure. Virtually all the LR deficit found in settlements (99.3\%) corresponds to properties that have a deficit of less than $30 \%$.

Table 1: Legal Reserve (LR) deficit, deforestable surplus, compensation-only surplus, total surplus and Legal Reserve balance $\left({ }^{1}\right.$ Surplus minus Deficit) in state of Pará by private property registered in the Environmental Rural Property Register (CAR) and rural settlements. Ajustar casas decimais na versão final.

\begin{tabular}{|c|c|c|c|c|c|c|}
\hline Categories & LR Classes & $\begin{array}{l}\text { LR Defict } \\
\text { (ha) }\end{array}$ & $\begin{array}{c}\text { LR } \\
\text { Defict } \\
(\%) \\
\end{array}$ & $\begin{array}{l}\text { LR Deforestable } \\
\text { surplus (ha) }\end{array}$ & $\begin{array}{l}\text { LR comp.-only } \\
\text { surplus (ha) }\end{array}$ & $\begin{array}{l}\text { LR total surplus } \\
\text { (ha) }\end{array}$ \\
\hline \multirow{5}{*}{ CAR } & $0-30 \%$ & 992,828 & 50.4 & 699,924 & $2,271,060$ & $2,970,984$ \\
\hline & $30-60 \%$ & 948,556 & 48.2 & - & 878,407 & 878,407 \\
\hline & $60-80 \%$ & 27,326 & 1.4 & - & 747,169 & 747,169 \\
\hline & $80-100 \%$ & - & - & - & 173,446 & 173,446 \\
\hline & Total & $1,968,710$ & 100 & 699,924 & $4,070,082$ & $4,770,006$ \\
\hline \multirow{5}{*}{$\begin{array}{l}\text { Rural } \\
\text { settlements }\end{array}$} & $0-30 \%$ & 298,297 & 99.3 & 656,762 & 375,984 & 375,984 \\
\hline & $30-60 \%$ & 1,047 & 0.3 & - & $1,266,943$ & $1,266,943$ \\
\hline & $60-80 \%$ & 1,046 & 0.3 & - & $3,801,909$ & $1,227,423$ \\
\hline & $80-100 \%$ & - & - & - & $1,756,305$ & $4,980,451$ \\
\hline & Total & 300,390 & 100 & 656,762 & $7,201,141$ & $7,850,802$ \\
\hline \multicolumn{2}{|c|}{ Sum of totals } & $2,269,100$ & - & $1,356,686$ & $11,271,223$ & $12,620,808$ \\
\hline LR Balance $^{1}$ & - & - & - & $-912,414$ & $9,002,123$ & $10,351,708$ \\
\hline
\end{tabular}



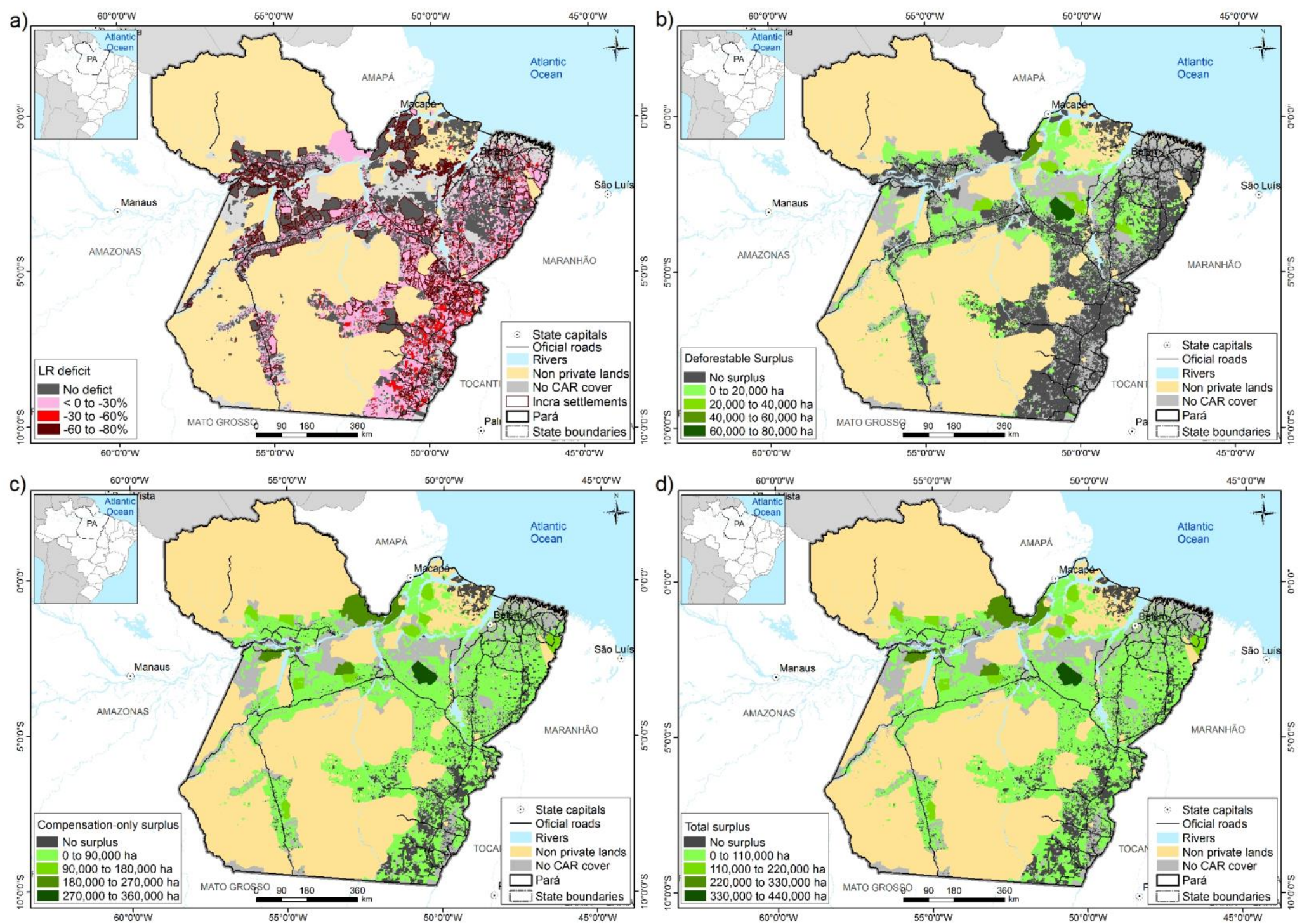
Figure 4: Distribution of Legal Reserve (as defined by the 2012 Brazilian Forest Code) in rural properties registered under CAR and settlements: a) deficit (forest cover under the required LR: negative values); b) deforestable surplus (forest cover over $80 \%$ of each property); c) compensation-only surplus (forest cover that can used for compensation purposes only but not deforested); d) total surplus (deforestable surplus and compensation-only surplus).

\subsection{Distribution of deforestable surplus and compensation-only surplus in Pará}

The deforestable surplus in Pará represents an area of 1.3 Mha (Figure 4b, Table 1). The Marajó region alone holds $36 \%$ of the deforestable LR surplus for the state (Table S5). The compensation-only surplus covers 11.2 Mha (Figure 4c, Table 1). From the total area of compensation-only surplus, 8.7 Mha (1.5 million from CAR and 7.1 million from settlements) is relative to the current forest cover of small properties and 2.5 Mha from medium and large properties with $50 \%$ to $80 \%$ of forest cover. Thus, the total surplus estimated in this study, including deforestable surplus and compensation-only surplus, is 12.6 Mha (Figure $4 \mathrm{~d}$, Table 1 ).

Accounting for both total surplus and total deficit the LR balance for the state gives a surplus of 10.3 Mha, due especially to the contribution of compensation-only surplus, which accounts for $17 \%$ of the private land area available for CAR registry in Pará (Figure 4; Table 1). Conversely, taking into account only the deforestable surplus, the LR balance for Pará would give a deficit of 912,414 ha (Table 1).

\subsection{Distribution of Legal Reserve deficit and total surplus across properties of different sizes}

Rural settlements account for the highest percentage of compensation-only surplus (96.7\% - 7.2 Mha), as a percentage of the required LR area for this category, followed by the three classes of small properties (Figure 5a; Table S4). Settlements also presented the highest percentage of deforestable surplus $(8.8 \%-656,762$ ha), followed by large and medium-sized properties. The LR deficit was mostly made up by medium $(22.6 \%$ - 605,900 ha) and large $(12.9 \%-1.2 \mathrm{Mha})$ properties, followed by the three classes of small properties (Figure 5a; Table S4) (Figure 5b; Table S4). 


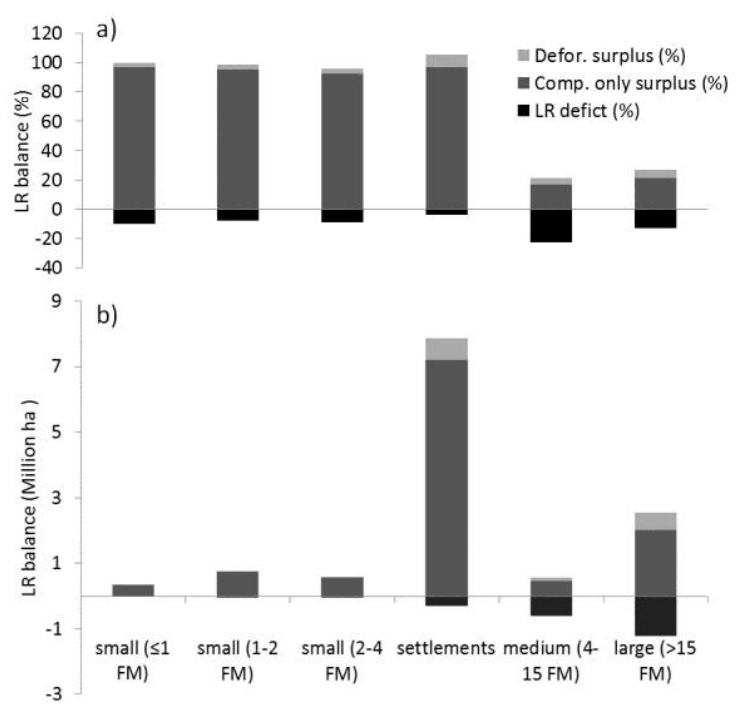

Figure 5: Legal reserve balance by property size as (a) a percentage of the required LR and (b) total area in the in the state of Pará. Property size is defined in terms of the number of fiscal modules (FM).

\subsection{Distribution of Legal Reserve deficit and total surplus across municipalities}

The Legal Reserve of each of the 144 municipalities in the state of Pará was calculated as the total surplus (compensation-only surplus and deforestable surplus) minus the total deficit per municipality (Legal Reserve balance). We found that 32 municipalities (22\% of the state total) presented more deficit than surplus (Figure 6; Table S6) - amounting to a total of 382,521 ha, or $17 \%$ of the total deficit in private properties in Pará. In all cases the deficit of these 32 municipalities could be compensated for by the surplus provided by one or more neighboring municipalities, if the landowners do not restore forest on open land within the same municipality where the deficit occurred. The remaining $83 \%$, or $1.8 \mathrm{Mha}$, of deficit that is distributed across 111 (77\% of the total) municipalities can be compensated within the same municipality if landowners choose not to restore on their own properties. Only one municipality (Santa Cruz do Arari) was mapped as neutral (no LR deficit or surplus) (Figure 6; Table S6). 


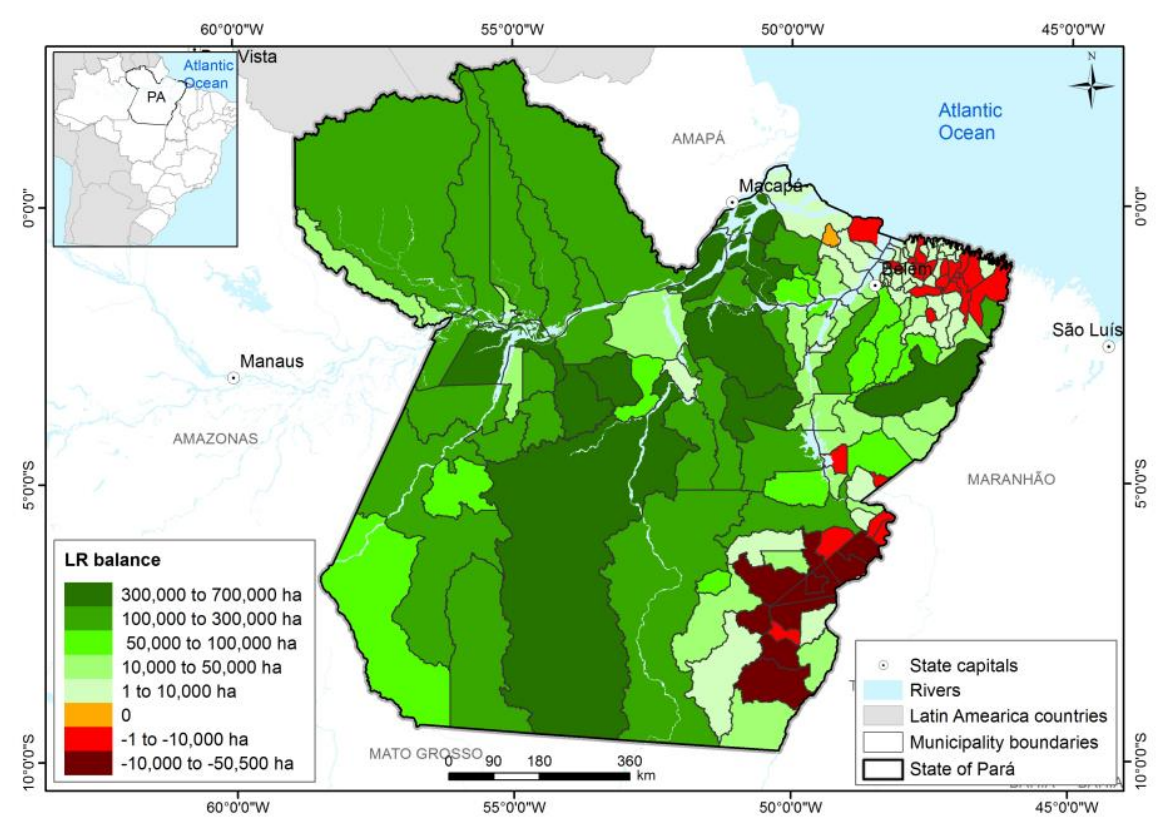

Figure 6: Legal Reserve balance (Surplus minus Deficit) by municipality, as a percentage of the adjusted LR requirement for each municipality, according to the updated Brazilian Forest Code. Positive values indicate Legal Reserve surplus is higher than the deficit area and negative values indicate Legal Reserve deficit is higher than the surplus area. Zero indicates neutral municipalities (no deficit or surplus).

\section{DISCUSSION}

Our estimate of the total LR surplus for the 35 Mha of registered properties (CAR and agrarian reform settlements - 58,835 properties) we assessed in Pará was more than five times the total area of deficit. Medium and large properties contributed the most to the total deficit area $(22.6 \%$ and $12.9 \%$, respectively), while agrarian reform settlements had comparatively large amounts of both compensation-only surplus and deforestable surplus. Of the municipalities that have properties in deficit, 111 could compensate their deficit with surplus areas within the same municipality while the remaining 32 could compensate from surplus areas in one or more of the neighboring municipalities, indicating that, in theory, compensation can always take place close to the source of the deficit. It is important to highlight that the vast majority (90\%) of LR surplus we mapped in Pará is compensation-only surplus that cannot be legally deforested. Furthermore, the opportunities given to the landowners to reduce a deficit are flexible and this makes it difficult to define or predict the alternative compliance pathways (i.e. blends of on-farm restoration and compensation from different regions) 
that are likely to be adopted and therefore their implications for the conservation of remaining forests.

\subsection{Legal Reserve deficit and surplus across Pará}

The distribution of LR deficit and surplus in Pará is clearly related to the historical land-use and occupation process in the region. The largest concentration of LR deficit in the State is located in its southeast region (Figure 4a), mostly due to economic activities such as cattle ranching, practiced in the region since the 1970s when the Brazilian government encouraged immigration and deforestation to guarantee land tenure. Areas where the agricultural frontier is less advanced and with large conservation units (e.g. Calha-Norte, northwest of Pará), and/or low population density (like Marajó), in part due to the inaccessible nature of these regions, still retain large amounts of LR surplus (Figure 4a).

The deficit and surplus found in agrarian settlements are associated with the nature of the settlements. For example, in Agro-Extractive Settlement Projects (PAE, in Portuguese) and Sustainable Development Settlements (PDS, in Portuguese), only low impact activities are allowed and represent the majority of the surplus area. In the Federal Settlements Project (PA, in Portuguese), agriculture and cattle ranching are the main activities (more associated with deforestation), and represent the majority of the deficit area (Figure 4a).

The total LR surplus of Pará, when taking account of both deforestable and compensation-only surplus, is more than five times the total area of deficit in the state. This suggests that the total surplus of Pará could compensate for its entire deficit (2.3 Mha) with 10.3 Mha still left over that can be traded with states within the same biome, for example, Mato Grosso, a neighboring state that has also experienced high historical rates of deforestation. This means that properties interested in trading LR surplus could, in theory, be located in areas that are ecologically very dissimilar or in different biogeographic regions. It is therefore important to understand the extent to which achieving legal compliance with the Forest Code through off-farm compensation is possible within the same or neighboring municipalities compared to more distant areas.

The fact that the LR surplus in Pará is made up almost entirely of forest areas that cannot be legally deforested has three important implications. The first is that the trading of these forests to compensate for illegal deforestation elsewhere brings no additional conservation benefit in and of itself. This is in contrast to the case of 
deforestable surplus that, if protected, could prevent primary forest from being cleared. The second is that these forests could provide a welcome income stream for farmers who have historically been more law abiding - including many smallholders. Finally, there is very little incentive for restoration activities, even in areas important for endemic biodiversity, or areas where the supply of ecosystem services is severely diminished. Given that when allowed by law (i.e. they have more than $80 \%$ forest cover) landowners still have more incentives to clear forest than rent deforestable land for compensation purposes, LR deficits are likely to be resolved through compensation-only surplus unless new incentives or conditions are created to encourage the protection of deforestable surplus through legal reserve trading.

\subsection{Achieving legal compliance across actors and municipalities and maximising returns for conservation}

The distribution of LR deficits and surpluses varies across properties of different sizes and between municipalities. Understanding this variability is key to assessing the potential for different actors to achieve legal compliance and hence the most appropriate mix of policy measures and incentives to ensure that regulations are enforced effectively and fairly (Godar et al., 2014). The relative contribution of total surplus and compensation-only surplus was greater for small properties and settlements; and the contribution of deforestable surplus was higher for rural settlements, suggesting that some of the poorest landowners would be able to receive an important income stream from landowners in deficit. This high proportion of compensation-only surplus in small properties can be partly explained by the fact that all current vegetation in small properties can be used to compensate deficit, compared to medium and large properties where only the portion of forest cover that is between $50-80 \%$ of each property can be used for the same purpose. In addition, smallholder-dominated areas generally contain more forest than areas dominated by large landowners who are more likely to engage in extensive cattle ranching and large-scale agriculture, and forests in smallholder dominated areas are usually less fragmented and degraded (Godar et al., 2014).

Under the updated Forest Code landowners have a range of options to reduce LR deficit, including: (i) the opportunity to compensate a deficit anywhere, as long as it is within the same biome where deficit occurred; (ii) use of both native vegetation and secondary forest in any stage of regeneration for compensation purposes; and (iii) 
restoration of forest on the farm which has the deficit instead of compensating in other places. These broad ranges of options have very different consequences for biodiversity conservation.

At the municipality scale, despite the 2.3 Mha of LR deficit found in Pará, 77\% of the municipalities (111) can compensate all of their deficit - amounting to $83 \%$ of the total deficit of the state in private properties- within the same municipality. This provides an important opportunity for the government to guide (whether through regulation or incentives) compensation and restoration actions to remain within the same municipality in order to maintain locally important ecosystem services and strengthen the conservation of regionally endemic and often endangered biodiversity. Furthermore, promoting legal reserve trading between neighboring municipalities can reduce the transaction costs of matching supply and demand for ad hoc agreements which are likely to dominate LR compensation mechanisms until a mature market system is in place. Nevertheless, $22 \%$ of the municipalities (32) have no choice but to compensate their LR deficit in other municipalities, owing to the lack of surplus locally. This deficit corresponds to $17 \%$ of the total deficit found in Pará, and in such cases it will be important to incentivize compensation within the same biogeographic regions.

Thus, efforts should be made to first ensure the protection of existing biodiversity and avoid further deforestation, and then to mitigate and compensate for impacts that have already occurred (McKenney and Kiesecker, 2010; Bull et al., 2013). Maximising the environmental benefits of achieving Forest Code compliance requires measures and considerations that go beyond the existing legal framework. These include (i) conservation of deforestable surplus, even where forests are degraded. To improve the potential conservation dividends from the compensation-only surplus the government could use the compensation regulatory system as a mechanism to avoid further deforestation of standing forests, e.g. through clear incentives or conditions to prioritize compensation with the remaining deforestable surplus; (ii) promotion of local compensation wherever possible. The net effects of achieving legal compliance through offsets that are not like for like (e.g. compensating in areas where the species composition is different) will result in an overall loss of biodiversity, particularly as the regions with the highest deficit lie within some of the most threatened areas of endemism, such as Belém, which contains more threatened species than anywhere else in the Brazilian Amazon (Moura et al., 2014); (iii) encourage avoidance of forest degradation and restoration actions in areas that are severely degraded. In addition to 
conservation actions to protect forest from being degraded, there could be advantages of encouraging local forest restoration in municipalities that would otherwise have to compensate remotely. This would help guarantee a reduction in forest fragmentation and an overall gain in ecological connectivity and habitat for forest species in the medium/long term.

\subsection{Technical challenges and barriers to addressing the Legal Reserve deficit in Pará}

A number of technical challenges must be addressed in order to obtain reliable assessments of environmental liabilities, facilitate law enforcement, monitoring and ensure that legal reserve deficits are fully and appropriately compensated. First, more accurate and representative georeferenced register of private properties (CAR) are required in the Amazon region. Despite the fact that the state of Para is the most advanced Brazilian state in registering its private properties in the CAR system (Whately and Campanili, 2013), many municipalities present large areas of unregistered private lands, such as Cametá (97\%) and Barcarena (93\%) (Green Municipalities Program and Government of the state of Pará, 2013). Furthermore, the Secretary of State for the Environment estimates that only 4,000 of approximately 100,000 properties registered in CAR in the state have been validated on the ground (Ausier, 2013). Thus, the CAR database presents many uncertainties regarding overlapping property boundaries, and the definition of legal reserve areas, productive land and APPs. For this reason, our analysis of existing CAR data may present potential issues with representativeness across the State, especially in the western region that encompasses most municipalities with CAR cover $<50 \%$, and is therefore likely to be the least representative coverage. However, this region also has the highest portion of protected areas and lowest deforestation pressure due to accessibility. We therefore believe that, even if the whole registerable area was mapped, the pattern of distribution of deficit and surpluses would not change significantly across the State.

Second, the accuracy of Geographic Information Systems (GIS) and remote sensing products are limited by the quality (or lack) of mapping data, especially in the Amazon region (Silva et al., 2013). Is this study we have not estimated deficit in APPs due to the lack of detailed (1:50.000) and reliable hydrological maps for Pará, which are required by law in Brazil (Decree $\mathrm{N}^{\circ}$ 7.830, 17 October 2012 for the National CAR System). Moreover, official data on land use and land cover for the Amazon are not 
always accurate, despite being the best available source of information at large spatial scales. We have estimated an area of 1 Mha detected by TerraClass as deforestation in 2008 and as secondary forest in 2010. In a 2-year-window it is unlikely that regenerating forests can be classified as secondary forest, as defined by the TerraClass systems as forests at an advanced stage of regeneration (Embrapa and INPE, 2011), implying a potential overestimate of secondary forest data. The age of secondary forest is important for law enforcement, because different ages of forest require different licenses for cleaning or deforestation (i.e. forests older than five years can be protected from deforestation, depending on its structure) (Normative Instruction $\mathrm{N}^{\circ} 08,03$ November 2015).

Finally, the complexity of Brazilian environmental laws have led to misunderstandings and controversies among different sectors (for example government, NGOs and farmers) on how to enforce the law and estimate legal liabilities (LR and APP deficits) (Ellinger and Barreto, 2012; Vale et al., 2014). Such controversies have resulted in legal actions from the Federal Prosecutor's Office against several articles of the Forest Code (Federal Prosecutor's Office, 2014).

It is important to note that Forest Code states that if deforestation occurred during a time when the law required a lower level of LR, then the land owners are exempt to restore or compensate forest if they complied with the legislation in force at the time (Art. 68). However, due to the lack of any property database for the past decades, these cases were not considered in the analysis. To benefit from this clause, the land owner must prove to the state Environmental Secretary the existence and size of the property at the time it was governed by a lower LR requirement. Although this is impossible to assess based on information that is currently available, we do not believe this limitation would change the overall results of this paper, since this rule is mostly applicable to regions where $80 \%$ of LR is required, which is a fairly small area ( $~ 8 \%$ of the state).

For a more complete diagnosis of LR deficit in the State, as required by law, more detailed mapping and assessment of APPs is essential to estimate the potential for forest restoration in Pará. Considering that the LR deficit in Pará could be completely compensated by compensation-only surplus areas, and the little (or lack) of incentive to retire areas of productive land or restore forests in the LR, restoration activities can be expected to be more focused in APPs, where it is mandatory, compared to LRs where it 
is voluntary. However, it is currently not possible to evaluate to what extent forests will be compensated or restored to achieve compliance with the Forest Code.

\section{CONCLUSIONS}

While Brazil has one of the most complex and advanced set of environmental laws, our results are relevant to the governance of forests on private lands in many other tropical forests nations. Wherever environmental laws require landowners to maintain a certain amount of forest cover, there are regulations regarding forest deficit or surplus that must be understood, and the implications of this balance for forest management at both local and large scales needs therefore to be assessed. In this study, we show that there was a significant LR surplus that is five times the deficit estimated in the state, despite the historical development of agriculture frontiers in Pará. That said the amount of forest available for compensation can only be considered a potential surplus because it is impossible say to what extent landowners will opt to compensate or restore to resolve the deficit of individual properties.

To maximize the conservation benefits of efforts to achieve compliance with the Forest Code additional measures are needed that are outside the existing legal framework. These include: the use of incentives or regulations to prioritize off-farm compensation in properties that still retain a deforestable surplus; encouraging off-farm compensation to happen as locally as possible to guarantee the protection of biodiversity in ecologically similar forests to those where the deficit occurs; and encouraging restoration of forests in areas where remnant forests are highly fragmented , as well as additional conservation actions to encourage avoidance of degradation in areas that are not under threat of deforestation but stand to be severely degraded from the impacts of logging and fire.

\section{ACKNOWLEDGEMENTS}

We thank the Porticus Fundation and World Resources Institute for supporting this research. We also thank Imazon team, especially Brenda Brito for support in the analysis. This is publication \#48 of the Sustainable Amazon Network publication series.

\section{References}

Ausier, M. (2013). SEMA-PA. Personal information. 
Barreto, P., Pinto, A., Brito, B. and Hayashi, S. (2008). Quem é o dono da Amazônia?: uma análise do recadastramento de imóveis rurais. Belém, Pará: Imazon. 72p.

Brazilian Federal Government. (2012a). Decree $N^{\circ}$ 7,830 from 17 October 2012. [Online]. Available at: http://www.planalto.gov.br/ccivil_03/_Ato20112014/2012/Decreto/D7830.htm.

Brazilian Federal Government. (2012b). Federal Law n 12,651, from 25 May 2012. [Online]. Available at: http://www.planalto.gov.br/ccivil_03/_Ato20112014/2012/Lei/L12727.htm.

Brazilian Ministry of the Environment and National Indian Foundation. (2013). Protected areas in state of Pará. Personal communication.

Brito, B. and Barreto, P. (2011). A regularização fundiária avançou na Amazônia?: os dois anos do programa Terra Legal. Belém, Pará: Imazon. 71p.

Bull, J. W., Suttle, K. B., Gordon, A., Singh, N. J. and Milner-Gulland, E. J. (2013). Biodiversity offsets in theory and practice. Oryx, 47 (03), p.369-380. [Online]. Available at: doi:10.1017/S003060531200172X.

Daily, G. C., Alexander, S., Ehrlich, P. R., Goulder, L., Lubchenco, J., Matson, P. A., Mooney, H. A., Postel, S., Schneider, S. H. and Tilman, D. (1997). Ecosystem services: benefits supplied to human societies by natural ecosystems, Issues in Ecology. 2nd ed. USA: Ecological Society of America. [Online]. Available at: http://www.esa.org/science_resources/issues/TextIssues/issue2.php [Accessed: 24 June 2013].

Ellinger, P. and Barreto, P. (2012). Código Florestal: como sair do impasse? Publicação, Belém, Pará: Imazon. [Online]. Available at: http://www.imazon.org.br/publicacoes/outros/codigo-florestal-como-sair-do-impasse [Accessed: 16 September 2014].

Embrapa and INPE. (2011). Levantamento de informações de uso e cobertura da terra na Amazônia.

Federal Prosecutor's Office. (2014). Justiça Federal declara inconstitucionalidade de artigo do novo Código Florestal. [Online]. Available at: http://www.prmg.mpf.mp.br/imprensa/noticias/meio-ambiente/copy_of_justica-federaldeclara-inconstitucionalidade-de-artigo-do-novo-codigo-florestal.

Ferreira, J., Pardini, R., Metzger, J. P., Fonseca, C. R., Pompeu, P. S., Sparovek, G. and Louzada, J. (2012). Towards environmentally sustainable agriculture in Brazil: challenges and opportunities for applied ecological research: Towards sustainable agriculture in Brazil. Journal of Applied Ecology, 49, p.535-541. [Online]. Available at: doi:10.1111/j.1365-2664.2012.02145.x.

Godar, J., Gardner, T. A., Tizado, E. J. and Pacheco, P. (2014). Actor-specific contributions to the deforestation slowdown in the Brazilian Amazon. Proceedings of the National Academy of Sciences, p.201322825. [Online]. Available at: doi:10.1073/pnas.1322825111. 
Green Municipalities Program. (2014). CAR no Estado. [Online]. Available at: http://municipiosverdes.com.br/ [Accessed: 11 February 2015].

Green Municipalities Program and Government of the state of Pará. (2013). Dados recentes. Green Municipalities Program. [Online]. Available at: http://www.municipiosverdes.com.br/relatorios/seleciona_tema/ficha_tematica [Accessed: 26 December 2013].

Grimaldi, M., Oszwald, J., Dolédec, S., Hurtado, M. del P., Miranda, I. de S., Sartre, X. A. de, Assis, W. S. de, Castañeda, E., Desjardins, T., Dubs, F., Guevara, E., Gond, V., Lima, T. T. S., Marichal, R., Michelotti, F., Mitja, D., Noronha, N. C., Oliveira, M. N. D., Ramirez, B., Rodriguez, G., Sarrazin, M., Jr, M. L. da S., Costa, L. G. S., Souza, S. L. de, Veiga, I., Velasquez, E. and Lavelle, P. (2014). Ecosystem services of regulation and support in Amazonian pioneer fronts: searching for landscape drivers. Landscape Ecology, 29 (2), p.311-328. [Online]. Available at: doi:10.1007/s10980-013-9981-y.

IBGE - Brazilian Institute of Geography and Statistics. (2013). Pecuária Efetivos/Rebanhos. [Online]. Available at: http://www.sidra.ibge.gov.br/bda/pecua/default.asp?t=2\&z=t\&o=24\&u1=1\&u3=1\&u4= $1 \& u 5=1 \& u 6=1 \& u 7=1 \& u 2=15$ [Accessed: 28 July 2015].

IBGE - Brazilian Institute of Geography and Statistics. (2014). Estados. [Online]. Available at: http://www.ibge.gov.br/estadosat/perfil.php?sigla=pa [Accessed: 22 January 2014].

Landau, E., Cruz, R., Hirsch, A., Pimenta, F. and Guimarães, D. (2012). Variação geográfica do tamanho dos módulos fiscais no Brasil. Embrapa. [Online]. Available at: http://www.infoteca.cnptia.embrapa.br/bitstream/doc/949260/1/doc146.pdf [Accessed: 3 March 2013].

McKenney, B. A. and Kiesecker, J. M. (2010). Policy Development for Biodiversity Offsets: A Review of Offset Frameworks. Environmental Management, 45 (1), p.165176. [Online]. Available at: doi:10.1007/s00267-009-9396-3.

MMA - Brazilian Ministry of the Environment. (2004). Plano de ação para a prevenção e controle de desmatamento. Brasília. [Online]. Available at: http://www.fundoamazonia.gov.br/FundoAmazonia/export/sites/default/site_pt/Galerias /Arquivos/Publicacoes/PPCDAM.pdf.

Moura, N. G., Lees, A. C., Aleixo, A., Barlow, J., Dantas, S. M., Ferreira, J., Lima, M. D. F. C. and Gardner, T. A. (2014). Two Hundred Years of Local Avian Extinctions in Eastern Amazonia. Conservation Biology, 28 (5), p.1271-1281. [Online]. Available at: doi:10.1111/cobi.12300.

Nasi, R., Wunder, S. and Campos, J. J. (2002). Forest ecosystem services: can they pay our way out of deforestation? New York: CIFOR, p.38. [Online]. Available at: http://scholar.google.com.br/scholar?hl=en\&as_vis=1\&q=forest+ecosystem+services\& btnG=\&as_sdt=1\%2C5\&as_sdtp= [Accessed: 24 June 2013].

Silva, P. H. A., Felix, I. M., Zacari, Milhomens, A., Menke, A., Oliveira, M. and Souza Jr, C. (2013). Desenvolvimento e implementação de metodologia para a automação e melhoria do processo de monitoramento e gestão de Áreas de Preservação Permanente 
ao longo dos cursos d'água para apoio ao Cadastro Ambiental Rural. In: Anais XVI Simpósio Brasileiro de Sensoriamento Remoto - SBSR, Foz do Iguaçu, PR, Brasil, 2013, Foz do Iguaçu, Paraná, Brazil: INPE, p.6861-6868. [Online]. Available at: http://www.dsr.inpe.br/sbsr2013/files/p1016.pdf.

Soares-Filho, B., Rajão, R., Macedo, M., Carneiro, A., Costa, W., Coe, M., Rodrigues, H. and Alencar, A. (2014). Cracking Brazil's Forest Code. Science, 344 (6182), p.363364. [Online]. Available at: doi:10.1126/science.1246663.

Soares-Filho, B. S. (2013). Impacto da revisão do Código Florestal: como viabilizar o grande desafio adiante? Brasília: Secretaria de Assuntos Estratégicos, p.28. [Online]. Available at: http://www.sae.gov.br/site/wp-content/uploads/Artigo-codigoflorestal.pdf.

Souza Jr., C., Amaral, P., Sales, M., Salomão, R., Oliveira Jr., L., Batista, W. and Martins, J. (2013). Base de informações geográficas para gestão ambiental municipal na Amazônia. Revista Brasileira de Cartografia, 3, p.591-603.

State Environmental Secretary. (2015). Personal information.

Vale, R., Lima, A. and Pinto, F. (2014). Muito dito e pouco feito. Observatório do Código Florestal. [Online]. Available at: http://www.observatorioflorestal.org.br/?p=1446.

Vieira, I. C. G., Gardner, T., Ferreira, J., Lees, A. C. and Barlow, J. (2014). Challenges of Governing Second-Growth Forests: A Case Study from the Brazilian Amazonian State of Pará. Forests, 5 (7), p.1737-1752. [Online]. Available at: doi:10.3390/f5071737.

Whately, M. and Campanili, M. (2013). Green Municipalities Program: lessons learned and challenges for 2013/2014. Belém, Pará: Green Municipalities Program and Pará state Government. [Online]. Available at: https://docs.google.com/file/d/0B4LOtiMjnDend1VyZzJXNnRyRlk/edit.

Zakia, M. J. and Pinto, L. (2013). Guia para a aplicação da nova lei florestal em propriedades rurais. Piracicaba, SP: Imaflora. [Online]. Available at: http://www.imaflora.org/downloads/biblioteca/52d7c3a819c3e_Guia_Aplicao_Nova_L ei_Florestal.pdf. 